\title{
Investigation and Improvement of Bond Performance of Synthetic Macro-Fibres in Concrete
}

\author{
Mantas Garnevičius ${ }^{1,2} \oplus^{\circ}$, Linas Plioplys ${ }^{1,2}$, Pui-Lam Ng ${ }^{2,3,4}$, Shaohua Chu ${ }^{4}$ (D) and \\ Viktor Gribniak 1,2,*iD \\ 1 Department of Steel and Composite Structures, Vilnius Gediminas Technical University (Vilnius Tech), \\ Saulètekio av. 11, LT-10223 Vilnius, Lithuania; Mantas.Garnevicius@vgtu.lt (M.G.); \\ Linas.Plioplys@vgtu.lt (L.P.) \\ 2 Laboratory of Innovative Building Structures, Vilnius Tech, Saulètekio av. 11, LT-10223 Vilnius, Lithuania; \\ irdngpl@gmail.com \\ 3 Laboratory of Concrete Technologies, Vilnius Tech, Sauletekio av. 11, LT-10223 Vilnius, Lithuania \\ 4 Department of Civil Engineering, The University of Hong Kong, Pokfulam, Hong Kong 999077, China; \\ shchu@connect.hku.hk \\ * Correspondence: Viktor.Gribniak@vgtu.lt; Tel.: +370-6-134-6759
}

Received: 18 November 2020; Accepted: 11 December 2020; Published: 13 December 2020

\begin{abstract}
Strength and stiffness are the key parameters characterising the bond performance of fibres in concrete. However, a straightforward procedure for estimating the bond parameters of a synthetic macro-fibre does not exist. This study employs pull-out tests to investigate the bond behaviour of synthetic macro-fibres. Two types of macro-fibres available in the market were investigated. A gripping system was developed to protect the fibres from local damage. The experimental campaign consisted of two stages. At the first stage, 32 concrete specimens were manufactured for performing 96 pull-out tests (three fibre samples were embedded in each cube perpendicular to the top surface and two sides). Two types of macro-fibres with either 10 or $20 \mathrm{~mm}$ embedment length were tested. The obtained load-displacement diagrams from pull-out tests demonstrate that the bond performance (characterised by the strength and deformation modulus) of the "top" fibres is almost $20 \%$ weaker than fibres positioned to the side surfaces. At the second stage, one type of macro-fibre was chosen for further experimentation of the feasibility of improving the bond performance through the use of colloidal silica or steel micro-fibres. This investigation stage employed an additional 36 concrete specimens. The use of steel micro-fibres was found to be an efficient alternative. The success of this solution requires a suitable proportioning of the concrete.
\end{abstract}

Keywords: synthetic macro-fibres; bond; pull-out test; colloidal silica; steel micro-fibres

\section{Introduction}

In contrast to bar reinforcement, fibres offer good potential to serve as dispersed reinforcement in concrete construction in the commonplace. The concept of the structural application of fibrous reinforcement had been laid down since the last century [1]. Compared to conventional reinforced concrete, fibre-reinforced concrete (FRC) can be superior in terms of crack resistance, ductility, and residual stiffness of the cracked elements [2,3]. The fibres have a significant role in controlling the widening and propagation of cracks. Structurally, the fibres prevent crack proliferation by transferring tensile stresses across the crack to tension along the fibres, as well as to the bond with surrounding concrete $[4,5]$. This crack bridging mechanism can increase the energy absorption in the post-crack regime and improve the ductility of FRC [6]. In structural engineering design, the RILEM recommendation [7] considers FRC as a homogeneous substance with modified material properties 
differing from conventional concrete. This simplified approach enables neither estimating the fibre interaction mechanisms nor identifying the causes of alteration of mechanical properties of FRC. Accurate analysis of FRC as a composite material is complicated by the variety of sources and physical parameters of fibres and concrete mix proportions [8]. The type, length, surface texture, and geometrical features of fibres, mechanical properties of the concrete, content of fibres in concrete, and maximum nominal size of aggregates influence the bond performance of the fibre as dispersed reinforcement $[9,10]$. Recent publications [11-19] demonstrated that combinations of synthetic and steel fibres are efficient in structural applications. However, there is generally the concern of inefficiency in load resistance of synthetic macro-fibres in structural use [19-21]. With the recent advances of synthetic materials, the tensile strength capacity of synthetic fibres can be comparable to that of metallic reinforcing bars. This development has broadened the application scope of synthetic fibres, especially in combined use with steel fibres [22,23].

It is known that the structural properties of FRC are highly dependent on the bond characteristics of fibres. Juhász [6] pointed out the essential difference between the interaction mechanisms of steel and synthetic fibres with concrete: while steel fibres pull-out from the matrix, synthetic fibres bridge the crack. Nevertheless, there is no universal methodology for evaluating the bond parameters of a synthetic macro-fibre [24,25]. To address this gap, the bond behaviour of synthetic macro-fibres in concrete is the targeted object of this research. The bond strength and deformation modulus together define the bond behaviour and indicate the interaction mechanism that is responsible for the residual strength of FRC - the primary property that describes the efficiency of structural application of the fibres. This study employs pull-out tests [26] to investigate the bond behaviour of synthetic macro-fibres, with the use of a gripping system developed by the authors' research team to prevent stress localisation and protect the fibres from local damage. Two types of synthetic fibres available in the market were included in the experimental campaign. The maximum pull-out force and corresponding slip, the total deformation energy, the maximum slip displacement, and the failure behaviour were studied and compared. One of the fibre types was rationally chosen for further analysis of the feasibility to improve the bond performance. To this end, adequate consideration was given to the strength of the fibre material necessary to activate the bond-slip mechanism. Innovative attempts to improve the bond performance were explored on this basis. These included the use of colloidal silica and the variation in the volumetric content of steel micro-fibres as the experimental parameters.

In the conventional practice, the employment of colloidal silica and steel micro-fibres are not often adopted as solutions for improving the bond performance of synthetic macro-fibres. Densification of the concrete at the fibre-concrete interface $[27,28]$ has provided a rationale for exploring the former solution. The effect of micro-fibres confining microstructural deformation of the concrete $[29,30]$ in the proximity motivated the latter solution. The steel micro-fibres develop a similar mechanism to macro-fibres as dispersed reinforcement to benefit the structural properties of FRC [31,32] but on a micro-scale. However, the presence of rigid steel fibres substantially reduced the workability of fresh concrete [33,34]. That has been a crucial reason limiting the use of steel fibrous concretes $[35,36]$. In this study, appropriate measures of concrete mix adjustment and optimisation were adopted to cope with the different volumetric contents of steel micro-fibres. The research results provide a valuable reference for developing efficient FRC.

\section{Experimental Campaign}

The testing program consists of two stages. In the first stage, pull-out tests were performed to determine the bond performance of two types of synthetic macro-fibres available in the market. In the second stage, one type of fibre was chosen for further experimentation of the feasibility of improving the bond performance. Remarkably, two non-conventional solutions were explored, namely, the use of colloidal silica and the use of steel micro-fibres.

Two fibre types (designated as Type- $A$ and Type- $B$ ) were included in the experimentation. Figure 1a shows these fibres. Type- $A$ fibre had a length of $45 \mathrm{~mm}$ and equivalent diameter of $0.9 \mathrm{~mm}$; it had 
tensile strength of $465 \mathrm{MPa}$ and elastic modulus of $3350 \mathrm{MPa}$. Type- $B$ fibre had a length of $40 \mathrm{~mm}$ and equivalent diameter of $0.7 \mathrm{~mm}$; it had tensile strength of $500 \mathrm{MPa}$ and elastic modulus of $6000 \mathrm{MPa}$. Comparatively, Type- $A$ fibre had a deeper texture of surface embossment than Type- $B$ fibre. The fibres were partially embedded in $100 \mathrm{~mm}$ cubes for pull-out testing; two bonding lengths (10 and $20 \mathrm{~mm}$ ) were considered. The test campaign encompassed four sets of specimens from the combination of two fibre types and two embedment lengths. Each set was experimentally investigated by testing with eight cubes. In total, 32 cube specimens were prepared. Three fibres (one on the top surface and two on the opposite side surfaces) were inserted in each cube, as shown in Figure 1b. The fibres were marked to indicate the correct embedment depth (Figure 1a). Expanded polystyrene was placed in the moulds (Figure 2) with fibres inserted before concreting (Figure 2a) to ensure the exact position of the "side" fibres (Figure 2b), whereas the "top" fibre was inserted manually into the specimen when the concrete was fresh (Figure 2c). The concrete was compacted by a vibration plate (Figure $2 \mathrm{~d}$ ) to achieve proper compaction. After curing and demoulding, the length of the unbonded part of the fibre outside the specimen concrete was measured to verify the actual embedment length.

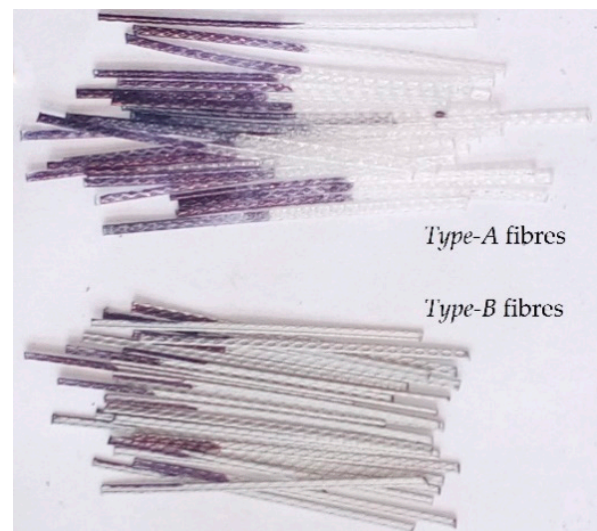

(a)

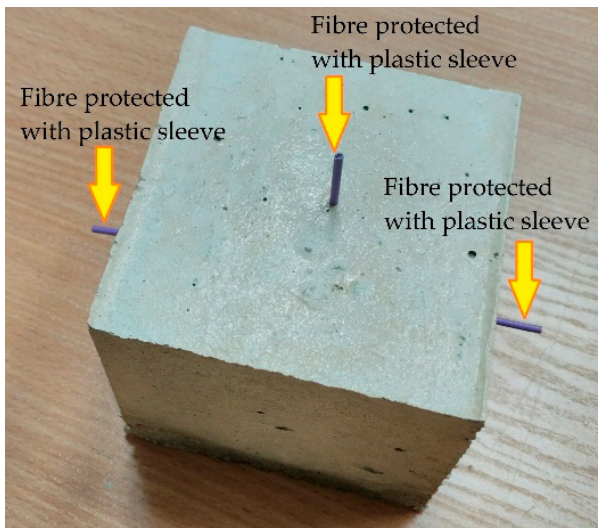

(b)

Figure 1. Specimens for pull-out test: (a) Type- $A$ and Type- $B$ fibres highlighting the embedment length; (b) a typical cube with embedded fibres.

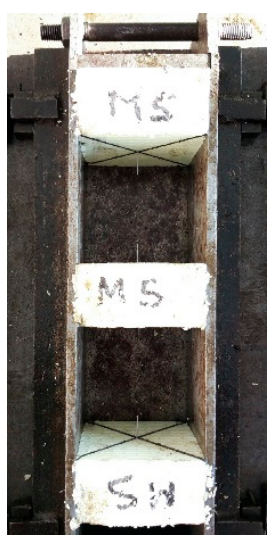

(a)

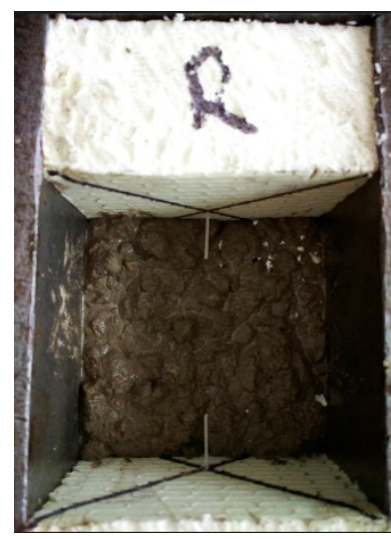

(b)

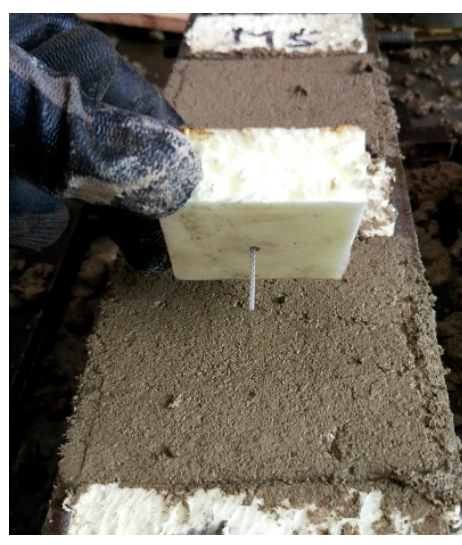

(c)

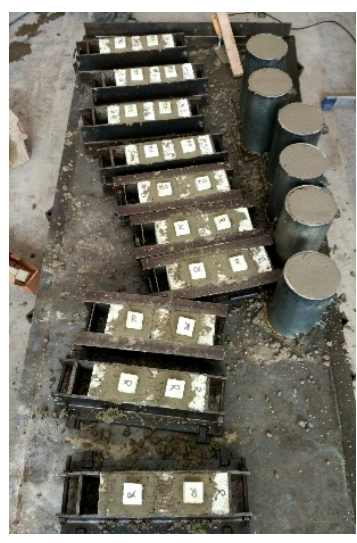

(d)

Figure 2. Preparing pull-out test specimens: (a) steel moulds with expanded polystyrene; (b) mould partially filled with concrete; (c) a manual placement of the top fibre; (d) specimen series after concreting.

All cube samples were produced from one concrete batch. Proportions of concrete are expressed in terms of contents of ingredients per cubic metre in the following: $300 \mathrm{~kg}$ of type CEM I $42.5 \mathrm{R}$ cement, $165 \mathrm{~kg}$ of water, $100 \mathrm{~kg}$ of limestone powder, $787 \mathrm{~kg}$ of $0 / 4 \mathrm{~mm}$ sand, and $988 \mathrm{~kg}$ of 4/16 mm crushed aggregates; $0.75 \%$ (by mass of the cement) of superplasticiser Mapei Dynamon XTend. The average 
slump of the fresh concrete was measured to be $180 \pm 35 \mathrm{~mm}$. Average compressive strength of the $100 \mathrm{~mm}$ concrete cubes measured at the 28-day age and the testing date of 153-day age was equal to 39.14 and 46.16 $\mathrm{MPa}$, respectively.

The former attempts to investigate the bond performance of synthetic macro-fibres [37] demonstrated the necessity of a reliable protection system for the polymeric fibre samples. Either loss of the cohesive contact with grips or slip of the protection sleeves would defeat the pull-out test and thus should be avoided. Figure 3 shows the typical examples of the preliminary tests. These unsuccessful results motivated the development of a gripping system to protect the fibres from local damage. In the same manner as applied previously [37], plastic sleeves (Figure 3a) were used for preserving the unbonded part of the fibres from damage. The mechanical properties (flexibility and friction coefficient) of the sleeves were chosen using the trial-and-error procedure. Adjustable steel clamps (Figure 4a) were additionally introduced to fix the protected fibre, preventing the localisation of stresses induced by the gripping system of the tension apparatus (Figure $4 b-d$ ).

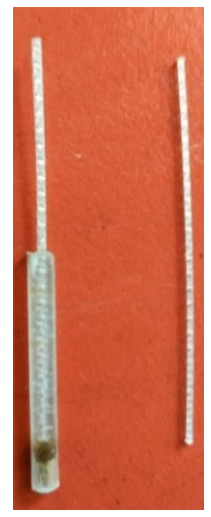

(a)

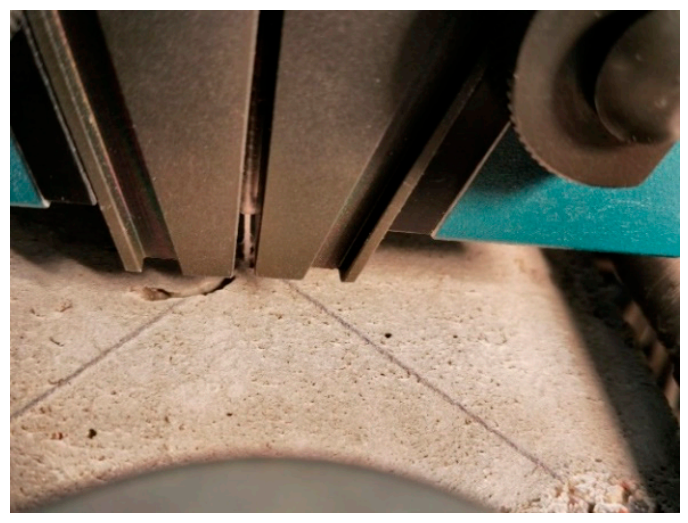

(b)

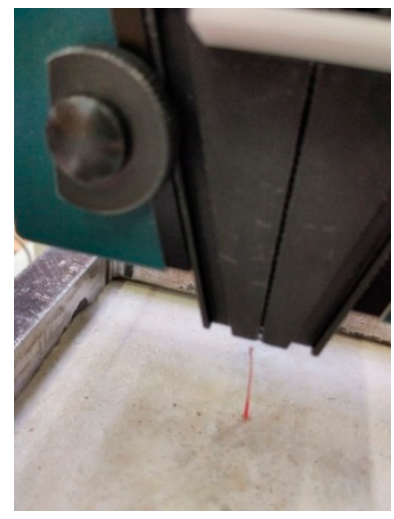

(c)

Figure 3. Preliminary pull-out tests of synthetic macro-fibres [37]: (a) fibres protected with plastic sleeve; (b) failure of the fibre samples due to slip of the protection sleeve; (c) loss of the cohesive contact with the grips.

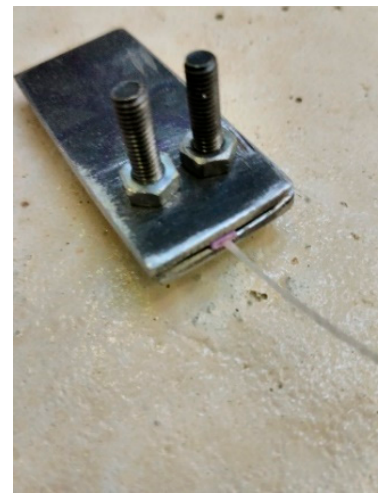

(a)

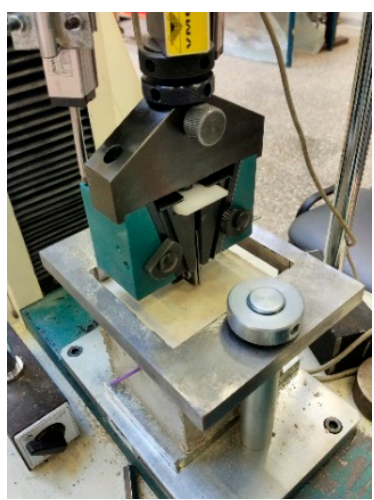

(b)

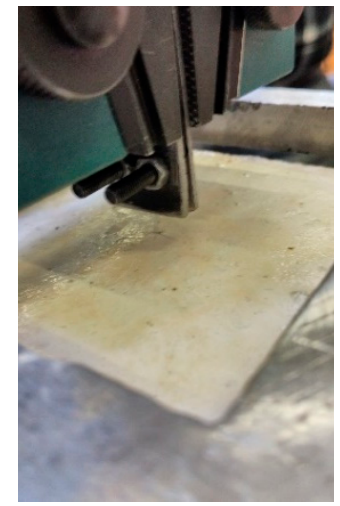

(c)

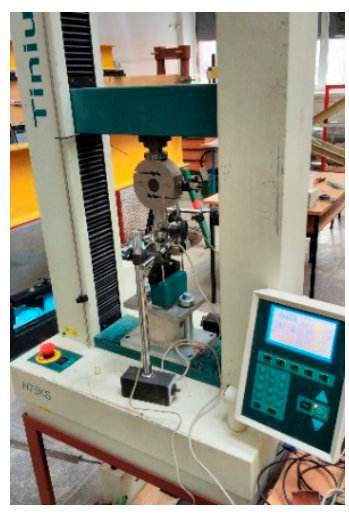

(d)

Figure 4. Gripping system: (a) steel clamps; (b) inventory grips by testing machine; (c) the steel clamps in the grips; (d) electromechanical testing apparatus H75KS.

The testing apparatus was a $75 \mathrm{kN}$ capacity electromechanical machine $H 75 \mathrm{KS}$ (Tinius Olsen, Norway). The fibre under testing was loaded in a deformation-control manner with $0.8 \mathrm{~mm} / \mathrm{min}$ loading rate. A $2 \mathrm{kN}$ load cell was employed to measure the applied load. Higher precision of measurement could be attained by using such a relatively small capacity load cell. Vertical displacements of the grips were monitored using linear variable differential transformers (LVDT), as shown in Figure 4d; 
an additional LVDT was installed to monitor the vertical movements of the cube specimen. Readings from all devices (LVDT and the load cell) were acquired every second through the signal processing equipment Almemo 2890-9 (manufacturer: Ahlborn Mess- und Regelungstechnik GmbH, Germany) and recorded by a workstation computer. Figure 5 a depicts examples of the tested samples of Type-B fibres.

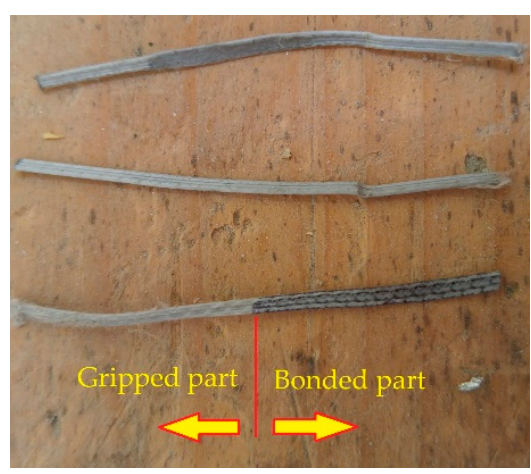

(a)

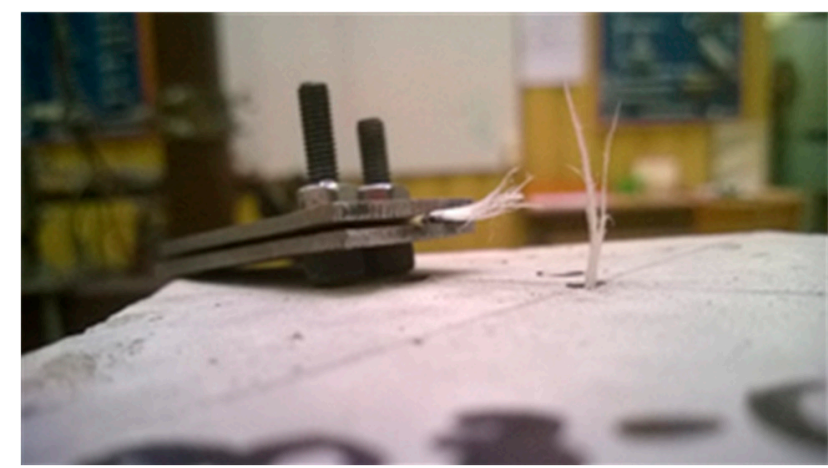

(b)

Figure 5. Pull-out test results: (a) tested fibre samples; (b) broken fibre protected with a plastic sleeve.

\section{Results of First Stage of Experimentation}

The pull-out specimens manifested three types of failure: (I) pull-out of fibre from the concrete (Figure 5a), which was taken as the normal failure mode; (II) failure of a fibre (Figure 5b), which signified premature breakage and should be excluded from the valid test results; (III) damage before the test (incoherent result), which should be excluded from the valid test results. Among these failure types, the latter mode is characteristic of the bond behaviour of the "top" fibres. That can be explained by the weakening of the bond due to sedimentation of the fresh concrete [38]. In all cases, the bond properties of the fibres inserted at top surfaces were inferior to those of the fibres positioned at the side surfaces. Moreover, the forces required to pull out the "top" fibres from the concrete were more scattered compared to the "side" samples. Thus, only the test results from the "side" fibres are employed for further analysis.

Table 1 summarises the test results including the embedment length $l_{e}$, the maximum pull-out force $\mathbf{P}_{\max }$, the corresponding slip displacement $u_{P}$, the total deformation energy $\delta$ (evaluated as the area beneath the load-displacement curve up to the maximum slip displacement), and the corresponding slip displacement $u_{\delta}$. This table only displays results of the fibres satisfactorily embedded in the concrete, i.e., the orientation of the fibre was normal to the concrete surface with negligible discrepancies in the length $l_{e}$ from the target value and without evident bond defects.

From Figure 5a, the pulled-out fibre surface was adhered with traces of cement paste, which accords with the expectation. Table 1 demonstrates that the energy dissipation capacity (the displacement energy $\delta$ ) of the Type- $A$ fibre was almost twice of that of the Type- $B$ fibre. Among these two types of fibres, the corresponding average energy $\delta$ released for the length $l_{e}=10 \mathrm{~mm}$ was respectively equal to 1077.4 and $533.9 \mathrm{Nmm}$; whereas for the length $l_{e}=20 \mathrm{~mm}$, the corresponding energy value was equal to 2671.7 and $1484.1 \mathrm{Nmm}$, respectively. Only the results of completely pulled out fibres were included in the averaging (the results of incompletely extracted fibres as highlighted in grey colour in Table 1 were excluded from the averaging).

Figure 6 shows the load-displacement diagrams of completely pulled out fibres. The scattering of fibre pull-out test results is in line with the behavioural norm [39-41], even though the specimens were prepared in good workmanship and quality. The scattered phenomenon is particularly true for the low stiffness synthetic macro-fibres in contrast to the more stiff metallic fibres and anchors $[6,42,43]$. Bond defects due to the heterogeneity of concrete were another possible cause of the observed scatter. For these reasons, testing of multiple specimens was required. 
Table 1. Summary of the pull-out test results ranged by deformation energy $\delta$.

\begin{tabular}{|c|c|c|c|c|c|}
\hline Fibre Type & $l_{e}[\mathrm{~mm}]$ & $\mathbf{P}_{\max }[\mathbf{N}]$ & $u_{P}[\mathrm{~mm}]$ & $\delta[\mathrm{Nmm}]$ & $u_{\delta}[\mathrm{mm}]$ \\
\hline$A$ & 10 & 198 & 4.48 & 1175.3 & 10 \\
\hline$A$ & 10 & 213 & 5.02 & 1153.7 & 10 \\
\hline$A$ & 10 & 190 & 2.61 & 1080.2 & 10 \\
\hline$A$ & 10 & 198 & 4.86 & 1039.5 & 10 \\
\hline$A$ & 10 & 176 & 4.90 & 938.3 & 10 \\
\hline$A$ & 10 & 224 & 4.76 & 330.8 & 5.55 \\
\hline$A$ & 20 & 234 & 5.90 & 2933.1 & 20 \\
\hline$A$ & 20 & 220 & 6.77 & 2661.9 & 20 \\
\hline$A$ & 20 & 229 & 6.56 & 2651.2 & 20 \\
\hline$A$ & 20 & 210 & 7.87 & 2440.2 & 20 \\
\hline$A$ & 20 & 238 & 8.62 & 903.6 & 8.64 \\
\hline$A$ & 20 & 240 & 5.88 & 886.2 & 6.30 \\
\hline A & 20 & 197 & 5.79 & 656.6 & 7.21 \\
\hline$B$ & 10 & 139 & 3.88 & 782.1 & 10 \\
\hline$B$ & 10 & 120 & 3.90 & 652.9 & 10 \\
\hline B & 10 & 109 & 5.39 & 578.8 & 10 \\
\hline$B$ & 10 & 98 & 3.00 & 535.3 & 10 \\
\hline$B$ & 10 & 91 & 4.88 & 455.7 & 10 \\
\hline$B$ & 10 & 71 & 3.06 & 442.1 & 10 \\
\hline$B$ & 10 & 84 & 3.62 & 415.0 & 10 \\
\hline$B$ & 10 & 86 & 2.48 & 409.1 & 10 \\
\hline$B$ & 20 & 178 & 4.39 & 2003.6 & 20 \\
\hline$B$ & 20 & 150 & 3.40 & 1437.8 & 20 \\
\hline$B$ & 20 & 152 & 3.28 & 1010.8 & 20 \\
\hline B & 20 & 119 & 4.01 & 372.8 & 5.25 \\
\hline$B$ & 20 & 141 & 4.74 & 267.3 & 4.95 \\
\hline
\end{tabular}

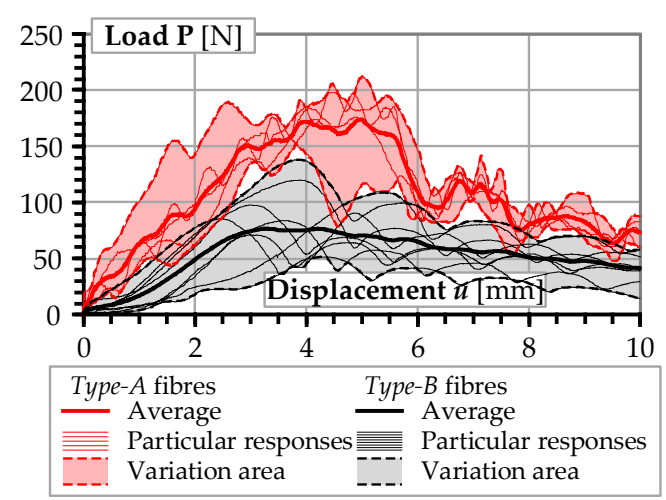

(a)

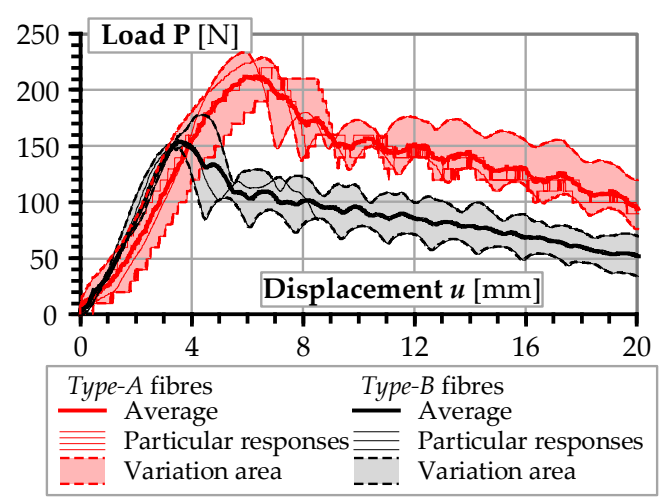

(b)

Figure 6. Load-displacement diagrams of the pull-out tests: (a) fibres with embedment length $l_{e}=$ $10 \mathrm{~mm}$; (b) $l_{e}=20 \mathrm{~mm}$.

Figure 6 reveals considerable differences in resistance of the alternative fibres. The increase in the embedment length $l_{e}$ (from 10 to $20 \mathrm{~mm}$ ) had distinct effects on the bond behaviour of different fibre types. Comparing the maximum pull-out forces (Table 1), the value of $\mathbf{P}_{\max }$ for Type- $A$ fibre was also on average almost twice of that for Type- $B$ fibre. This was due to the larger cross-sectional area of Type- $A$ fibre as well as the deeper texture of surface embossment that led to better interlocking with the surrounding concrete [44]. In view of its more superior mechanical properties, Type- $A$ fibre was chosen for examining the feasibility of improving the bond performance. 


\section{Results of Second Stage of Experimentation}

In the second stage of the study, an additional 36 concrete specimens were employed. There were two solutions attempted for improving the bond performance of the chosen synthetic macro-fibres. Firstly, the effectiveness of colloidal silica as a chemical additive was investigated. Secondly, the volumetric content of steel micro-fibres was investigated. The procedures of pull-out tests were the same as the first stage and are described in Section 2. For the reason explained earlier, only the results of the "side" fibres were considered.

\subsection{Use of Colloidal Silica}

During the first attempt, a colloidal silica with the trademark TCAM10 supplied by TеснConCRETE was investigated as a chemical additive for potentially improving the bond properties. This additive was a liquid containing up to $50 \%$ of silicon dioxide, and it densifies the microstructure of concrete by reacting with the portlandite to form additional calcium-silicate-hydrate in the interstitial pores of hardened concrete $[27,28,45]$. The use of TCAM10 is expected to improve the bond of fibres with the cementitious matrix. Table 2 describes the mix proportions of the concretes with and without colloidal silica added. The test program employed two groups of $100 \mathrm{~mm}$ cube specimens, where each group consisted of 12 concrete cubes.

Table 2. Mix proportions of concrete with colloidal silica $\left[\mathrm{kg} / \mathrm{m}^{3}\right]$.

\begin{tabular}{ccc}
\hline Component & Mix 1 & Mix 2 \\
\hline Cement CEM I 42.5 R & 298.7 & 298.7 \\
Water & 164.3 & 162.3 \\
Gravel 4/16 mm & 983.8 & 983.8 \\
Sand 0/4 mm & 783.7 & 783.7 \\
Limestone & 99.6 & 99.6 \\
Colloidal silica TCAM10 & - & 2.0 \\
Superplasticiser Mapei Dynamon XTend & 2.234 & 2.234 \\
\hline \multicolumn{2}{c}{ The proportions are similar to the concrete used in Section 2. }
\end{tabular}

Two embedded lengths (i.e., 10 and $20 \mathrm{~mm}$ ) of Type- $A$ fibres were included in the testing regime. Pull-out tests were conducted for fibres embedded in the reference concrete mix without colloidal silica (Mix 1) and the concrete mix containing colloidal silica (Mix 2). For Mix 1, the maximum pull-out force and average pull-out force of Type- $A$ fibres with $10 \mathrm{~mm}$ embedment length were respectively 185 and $70 \mathrm{~N}$, and the corresponding values of Type- $A$ fibres with $20 \mathrm{~mm}$ embedment length were respectively 260 and $125 \mathrm{~N}$. For Mix 2, the maximum pull-out force and average pull-out force of Type- $A$ fibres with $10 \mathrm{~mm}$ embedment length were respectively 165 and $60 \mathrm{~N}$, and the corresponding values of Type- $A$ fibres with $20 \mathrm{~mm}$ embedment length were respectively 290 and $130 \mathrm{~N}$. Therefore, the test results indicated no significant difference between Mix 1 and Mix 2 concrete specimens. The observed differences did not exceed $5 \%$, which was insignificant considering the scatter of the results. These outcomes demonstrate that the application of TCAM10 colloidal silica does not affect the bond behaviour of synthetic macro-fibres in concrete.

\subsection{Use of Steel Micro-Fibres}

During the second attempt, the application of steel micro-fibres Dramix OL 13/.16 manufactured by BEKAERT (Figure 7) was investigated for potential improvement of the bond performance of the synthetic macro-fibre [29,46]. The steel micro-fibres had a diameter of $0.16 \mathrm{~mm}$ and a length of $13 \mathrm{~mm}$. The surface of the fibre was of a smooth texture and had a layer of protective copper coating applied in the factory. The fibre had a permissible tensile strength of $2000 \mathrm{MPa}$. The raw material of the steel micro-fibres was recycled from steel wires for the tire manufacturing industry. In this study, two volumetric contents of the steel micro-fibres (i.e., $0.5 \%$ and $1.0 \%$ ) were dosed. 


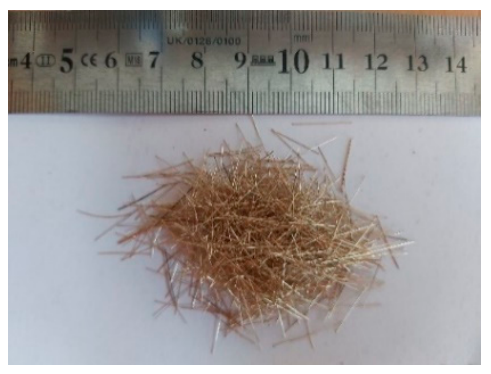

Figure 7. Dramix OL 13/.16 steel micro-fibres.

Due to the rigidity of the fibre material, the presence of steel micro-fibres reduces the workability of concrete. Pilot trial suggested that the concrete mix in the first investigation stage could not be directly employed [37]. To attain adequate workability for proper casting and compaction, a concrete mix of better workability has to be used with the steel micro-fibres. In designing a suitable concrete mix for addition of steel micro-fibres, the reference concrete Mix 1 in Table 2 was adopted as the starting point for the trial. The slump of concrete measured in accordance with European Standard EN 12350-2:2011 in Section 2 was approximately $180 \mathrm{~mm}$. Figure 8 depicts the trial mixing results. The initial addition of the steel micro-fibres reduced the slump to $110 \mathrm{~mm}$ (Figure 8a). The superplasticiser dosage was increased with an intent to restore sufficient workability. To avoid the segregation problem of the paste due to an excessive dosage of the superplasticiser (Figure 8b), other measures were adopted, which included reducing the maximum size of aggregates and angularity of aggregate particles. Accordingly, the mix proportioning was adjusted to achieve a consistent concrete mix (Figure 8c). The optimal superplasticiser dosage was obtained through a trial procedure, such that the concrete mixes had ample workability to ensure thorough mixing and uniform distribution of steel micro-fibres and, at the same time, there was no segregation problem.

Table 3 describes the final proportions and physical properties of the concretes adopted for steel micro-fibres addition. Among these, Mix 3a contained a fibre content of $0.5 \%$ by volume and Mix $3 \mathrm{~b}$ contained a fibre content of $1.0 \%$ by volume. During concrete mixing, the solid ingredients except the steel micro-fibres were first mixed with half of the water and superplasticiser mixture, and then the fibres and remaining mixture of water and the superplasticiser were added and thoroughly mixed. Two concrete cube specimens were produced from each concrete mix for pull-out testing. Three synthetic macro-fibres were inserted in each cube, as described in Section 2, and only the results from the "side" fibres were considered. The pull-out tests were carried out at the concrete age of 30 days. Average compressive strength of the $100 \mathrm{~mm}$ concrete cubes cast from Mix 3, Mix 3a, and Mix 3b was equal to $54.7,57.7$, and $48.0 \mathrm{MPa}$, respectively.

Table 3. Mix proportions and physical properties of concrete with steel micro-fibres.

\begin{tabular}{cccc}
\hline Component & Mix 3 & Mix 3a & Mix 3b \\
\hline Cement CEM I 42.5 R $\left[\mathrm{kg} / \mathrm{m}^{3}\right]$ & 396.0 & 396.0 & 396.0 \\
Water $\left[\mathrm{kg} / \mathrm{m}^{3}\right]$ & 204.0 & 203.0 & 203.0 \\
Gravel $2 / 5 \mathrm{~mm}\left[\mathrm{~kg} / \mathrm{m}^{3}\right]$ & 960.0 & 945.0 & 945.0 \\
Sand 0/4 $\mathrm{mm}\left[\mathrm{kg} / \mathrm{m}^{3}\right]$ & 1038.0 & 1022.0 & 1022.0 \\
Limestone $\left[\mathrm{kg} / \mathrm{m}^{3}\right]$ & 198.0 & 198.0 & 198.0 \\
Superplasticiser Mapei Dynamon XTend $\left[\mathrm{kg} / \mathrm{m}^{3}\right]$ & 6.0 & 7.0 & 7.0 \\
Steel micro-fibres [kg/m $\left.\mathrm{m}^{3}\right]$ & - & 47.0 & 94.0 \\
Slump [mm $\left.{ }^{1}\right]$ & 160 & 165 & 145 \\
Compressive strength [MPa] & 54.71 & 57.68 & 47.95 \\
\hline
\end{tabular}

${ }^{1}$ Slump of fresh concrete after dosing with steel micro-fibres. 


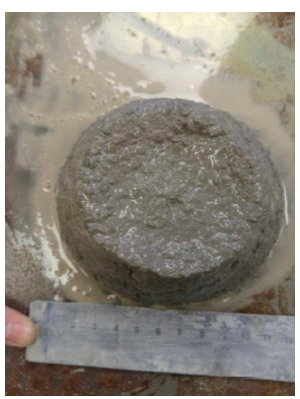

(a)

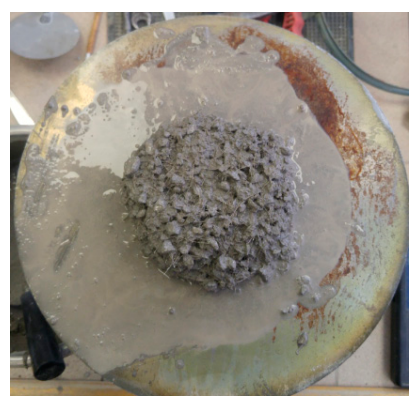

(b)

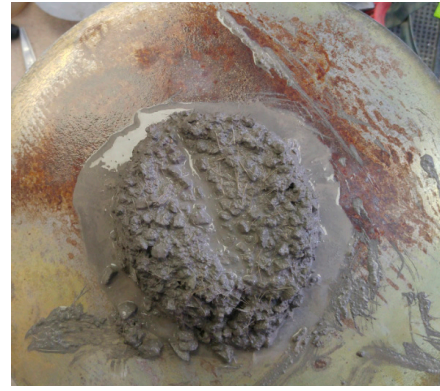

(c)

Figure 8. Slump tests during trial mixing: (a) $0.5 \%$ steel micro-fibre content with $2.2 \mathrm{~kg} / \mathrm{m}^{3}$ superplasticiser; (b) segregation of paste in the concrete with $0.5 \%$ steel micro-fibres at an interim stage of trial mixing; (c) Mix 3b (Table 3).

Figure 9 shows the results of pull-out tests of the synthetic fibres embedded in concrete containing steel micro-fibres. Table 4 summarises the test results, including the maximum pull-out force $\mathbf{P}_{\text {max }}$ and the corresponding slip displacement $u_{P}$, the total deformation energy $\delta$ (evaluated as the area beneath the load-displacement curve up to the maximum slip displacement), and the corresponding slip displacement $u_{\delta}$. The outcome from the broken fibre is highlighted in grey colour in the table. This result was excluded from Figure 9.

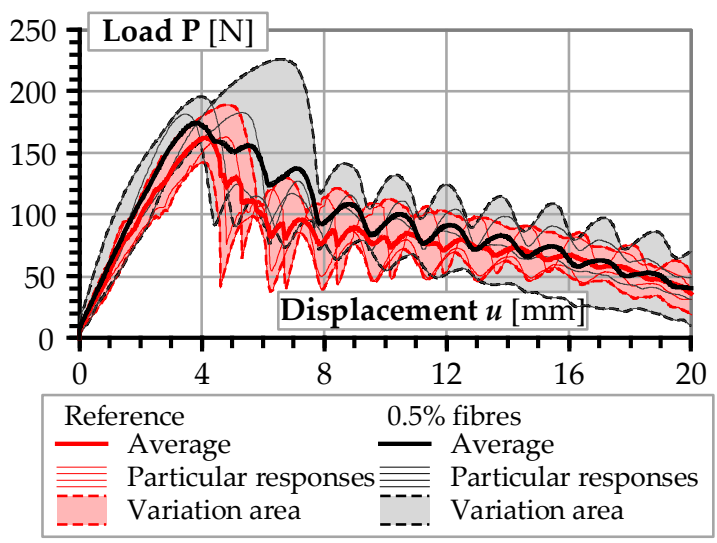

(a)

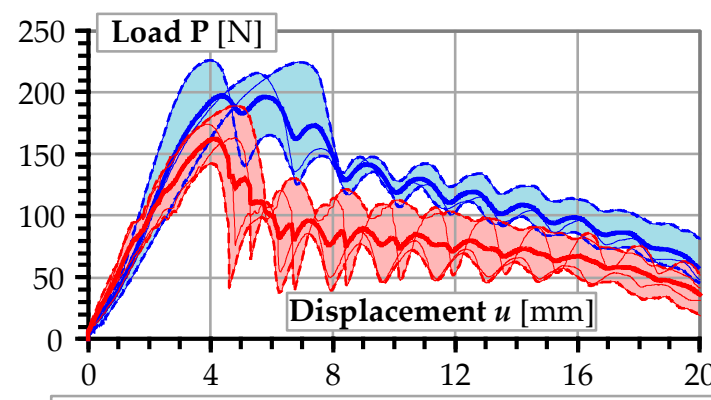

\begin{tabular}{|c|c|}
\hline Reference & $1.0 \%$ fibr \\
\hline Average & $\longrightarrow \mathrm{Av}$ \\
\hline Particular responses & cular responses \\
\hline Variation area & Variation area \\
\hline
\end{tabular}

(b)

Figure 9. Comparison of the pull-out test results of reference concrete (red lines) and concrete containing steel micro-fibres (black lines): (a) with fibre content of $0.5 \%$; (b) with fibre content of $1.0 \%$.

Table 4. Summary of the bond improvement results of Type- $A$ fibres with $l_{e}=20 \mathrm{~mm}$.

\begin{tabular}{ccccc}
\hline Fibre Content & $\mathbf{P}_{\text {max }}[\mathbf{N}]$ & $\boldsymbol{u}_{\boldsymbol{P}}[\mathbf{m m}]$ & $\delta[\mathbf{N m m}]$ & $\boldsymbol{u}_{\boldsymbol{\delta}}[\mathbf{m m}]$ \\
\hline- & 142.8 & 4.01 & 1267.5 & 20 \\
- & 175 & 3.95 & 1523.6 & 20 \\
- & 163.8 & 4.79 & 1706.2 & 20 \\
- & 189.3 & 4.81 & 2056.4 & 20 \\
$0.5 \%$ & 195.5 & 4.03 & 1481.7 & 20 \\
$0.5 \%$ & 226 & 6.61 & 2394.2 & 20 \\
$0.5 \%$ & 181.7 & 3.53 & 1713.5 & 20 \\
$0.5 \%$ & 183 & 5.35 & 1927.9 & 20 \\
$1.0 \%$ & 225.2 & 6.96 & 2289.7 & 20 \\
$1.0 \%$ & 183.2 & 2.92 & 363.2 & 3.18 \\
$1.0 \%$ & 226.7 & 4.03 & 2589.7 & 20 \\
$1.0 \%$ & 215.8 & 5.59 & 2288.7 & 20 \\
\hline
\end{tabular}


Table 4 illustrates the effect of the addition of the steel micro-fibres. There is a significant positive relationship between the fibre content and the deformation energy. On average, the deformation energy associated with the pull-out of the synthetic macro-fibre from the plain concrete was $1638.4 \mathrm{Nmm}$. The value of deformation energy increased to 1879.3 and $2389.4 \mathrm{Nmm}$, respectively, for $0.5 \%$ and $1.0 \%$ contents of the steel fibres. The maximum pull-out force $\mathbf{P}_{\max }$ required to pull out the synthetic fibre also increased upon addition of steel micro-fibres. An increase in maximum pull-out force by $10 \%$ (from 175 to $190 \mathrm{~N}$ ) and by $30 \%$ (from 170 to $225 \mathrm{~N}$ ) corresponding to the fibre contents of $0.5 \%$ and $1.0 \%$ was obtained upon averaging the results across similar specimens. The bond stiffness of the synthetic macro-fibre was enhanced by the addition of steel micro-fibres. Taking the secant bond stiffness at peak pull-out force (equal to $\mathbf{P}_{\max } / u_{P}$ ) as the basis of comparison, on average, the secant bond stiffness at peak pull-out force was increased by $25.9 \%$ and $26.8 \%$ upon adding $0.5 \%$ and $1.0 \%$ of steel micro-fibres, respectively. The increase in bond stiffness can effectively reduce the micro-crack width under pull-out action, which is advantageous to the structural performance of FRC.

\section{Discussion of the Results}

Reliable experimental results have been obtained from the series of pull-out testing. At this juncture, it is noteworthy that from the structural design perspective, the structural behaviour of FRC is dependent on the interaction between concrete and multiple distributed fibres as a composite, rather than the bond of a single fibre. Indeed, the number of fibres crossing a crack is a crucial factor determining the efficiency of the dispersed reinforcement. In this context, each $100 \mathrm{~g}$ batch of fibres approximately contains 3840 Type- $A$ fibres or 6900 Type- $B$ fibres. Though Type- $A$ fibres were able to resist higher pull-out force per single fibre, the larger number of Type- $B$ fibres were beneficial in promoting structural efficiency. The choice of fibre type for optimal performance in different structural applications will be a valuable topic for further research. Moreover, the structural efficiency of other types of synthetic macro-fibres could be examined by undergoing the test campaign considering the present research work as the reference.

The use of colloidal silica and steel micro-fibres in producing concrete specimens for the pull-out test yielded results with disparity, and an account of the interpretation is presented in the following. These reported findings are valuable since such experimental means had been rarely explored in the past. It was expected that the pore densification of colloidal silica could improve the matrix microstructure at the interface between the synthetic macro-fibre and concrete. However, the absence of pull-out force enhancement illustrated that the adhesion component of the bond [47] might not play a crucial role in resisting against the slip. During the experimentation, the dosage of colloidal silica recommended by the manufacturer and supplier was adopted. Nevertheless, increasing the dosage of colloidal silica may yield a positive effect. Further research is recommended for experimentation with a higher dosage.

On the contrary, the steel micro-fibres were capable of improving the bond strength of synthetic macro-fibres. The reason would be that the steel micro-fibres provided confinement against microstructural deformation in the concrete. The comparative analysis of Figures $6 \mathrm{~b}$ and $9 \mathrm{~b}$ reveals essential similarity in the bond behaviour of synthetic macro-fibres in concrete. Proper proportions of steel micro-fibres and fine aggregates produced a comparable effect on the bond resistance as the application of coarse aggregates (the respective average deformation energy was equal to 2389.4 and $2671.7 \mathrm{Nmm}$ ). The reduction in the steel fibre content from $1.0 \%$ to $0.5 \%$ reduced the deformation energy released during the debonding of the synthetic macro-fibres from 2389.4 to $1879.3 \mathrm{Nmm}$, though the corresponding compressive strength of the concrete increased from 48.0 to $57.7 \mathrm{MPa}$ (Table 3).

The above observations suggest that the mechanical interlock component [47] plays a predominant role in the pull-out resistance of synthetic fibres. There existed a distinct difference between the pull-out behaviour of metallic fibres and anchors [48-50], the underlying reason being the difference in material stiffness. The higher stiffness of the latter could mobilise the shear cone resistance of concrete and possibly lead to cone failure of concrete eventually. On the other hand, due to the low stiffness of 
synthetic macro-fibres, the slippage mechanisms are activated at a more advanced deformation stage, compared to steel fibres [6]. The reduction in the cross-section of the synthetic fibre due to the Poisson effect would diminish the bond interaction as well as the significance of the adhesion component.

Steel micro-fibres, through improving the mechanical properties of concrete [30] and mobilising a larger volume of concrete to anchor the macro-fibre against pull-out [51], could possibly exert synergetic effect with the synthetic macro-fibre. Such synergetic effect is worthwhile for more in-depth research. Overall, the present study has yielded useful results for developing efficient FRC.

There are some issues in concrete technology that deserve attention: the steel micro-fibres demand high workability of the concrete for proper mixing and uniform fibre distribution, and this affects the concrete mix proportioning. At a given water to cementitious materials ratio to satisfy the strength requirement, since an excessive dosage of superplasticiser would lead to the risk of segregation, the superplasticiser could not be added inadvertently. In this study, aggregates with reduced maximum aggregate size and less angularity were used. This was helpful in reducing the superplasticiser demand and successfully resulted in good quality steel micro-fibre concretes.

\section{Conclusions}

This manuscript has presented the investigation of the bond behaviour of synthetic macro-fibres. The experiment encompassed two types of synthetic macro-fibres available in the market. A bespoke gripping system newly developed to protect the fibres from local damage was employed for conducting the pull-out testing. The experimental campaign consisted of two stages. The mechanical performance of the bond was the research object in the first investigation stage. In the second investigation stage, one fibre type was chosen for examining the possibility of improving the bond performance. The following conclusions are drawn from the experimental findings:

- The loading capacity (the displacement energy $\delta$ ) of the Type- $A$ fibre was almost twice of that of the Type- $B$ fibre. The average deformation energy $\delta$ dissipated for the length $l_{e}=10 \mathrm{~mm}$ for Type- $A$ and Type- $B$ fibres was equal to 1077.4 and $533.9 \mathrm{Nmm}$; whereas for the length $l_{e}=$ $20 \mathrm{~mm}$, the deformation energy for the two types of fibres was equal to 2671.7 and $1484.1 \mathrm{Nmm}$, respectively. Thus, Type- $A$ fibres were chosen for further investigation of the feasibility to improve the bond performance.

- The application of colloidal silica with the dosage adopted in this study was found to be inefficient in improving the bond strength of synthetic macro-fibres in concrete. The observed differences in the maximum pull-out forces did not exceed $5 \%$, which was insignificant (in the statistical sense) in consideration of the inherent scatter of results.

- The use of steel micro-fibres was an effective measure to improve the bond performance. By adding $0.5 \%$ and $1.0 \%$ of steel micro-fibres by volume of concrete, the maximum pull-out force of synthetic fibres increased by $10 \%$ and $30 \%$, respectively, upon averaging the results across similar specimens. The respective values of deformation energy also increased by $15 \%$ and $45 \%$. The steel micro-fibres improved the bond by possibly enhancing the mechanical interlock component of the slip resistance of the synthetic macro-fibre. Nevertheless, the use of steel micro-fibres requires special attention in the mix proportioning of concrete.

- The test results demonstrated that the mechanical interlock component of bond plays a predominant role in the pull-out resistance of synthetic macro-fibres. Proper proportions of steel micro-fibres and fine aggregates produced a comparable effect on the bond performance as the application of coarse aggregates (the respective average deformation energy was equal to 2389.4 and $2671.7 \mathrm{Nmm}$ ). The reduction in the steel fibre content from $1.0 \%$ to $0.5 \%$ reduced the deformation energy from 2389.4 to $1879.3 \mathrm{Nmm}$, though the corresponding compressive strength of the concrete increased from 48.0 to $57.7 \mathrm{MPa}$.

Author Contributions: Conceptualisation V.G. and P.-L.N.; methodology V.G.; validation M.G. and P.-L.N.; formal analysis M.G.; investigation M.G. and L.P.; resources V.G. and S.C.; data curation M.G.; writing-original 
draft preparation M.G.; writing—review and editing V.G. and P.-L.N.; software S.C.; visualisation M.G. and L.P.; supervision V.G.; project administration M.G.; funding acquisition V.G. All authors have read and agreed to the published version of the manuscript.

Funding: This project has received funding from the European Regional Development Fund (Project No. 01.2.2-LMT-K-718-03-0010) under grant agreement with the Research Council of Lithuania (LMTLT). The APC was funded by Vilnius Tech.

Conflicts of Interest: The authors declare no conflict of interest.

\section{References}

1. Rabinovich, F.N. Concrete with Dispersed Reinforcement; A.A. Balkema: Rotterdam, The Netherlands, 1996.

2. Johnston, C.D. Fiber-Reinforced Cements and Concretes; Gordon \& Breach: Amsterdam, The Netherlands, 2001.

3. The Concrete Society. Guidance on the Use of Macro-Synthetic-Fibre-Reinforced Concrete; Technical Report No. 65; The Concrete Society: Surrey, UK, 2007.

4. Mobasher, B. Mechanics of Fiber and Textile Reinforced Cement Composites; CRC Press: Boca Raton, FL, USA, 2012.

5. Zhu, C.J.; Fang, S.; Ng, P.L.; Pundiene, I.; Chen, J.J. Flexural behavior of reinforced concrete beams strengthened by textile reinforced magnesium potassium phosphate cement mortar. Front. Mater. 2020, 7, 272. [CrossRef]

6. Juhász, K.P. The effect of the synthetic fibre reinforcement on the fracture energy of the concrete. IOP Conf. Ser. Mater. Sci. Eng. 2019, 613, 012037. [CrossRef]

7. Vandewalle, L.; Nemegeer, D.; Balazs, L.; Barr, B.; Bartos, P.; Banthia, N.; Brandt, A.; Criswell, M.; Denarie, E.; Di Prisco, M. $\sigma-\varepsilon$ Design Method. Mater. Struct. 2003, 36, 560-567.

8. Bentur, A.; Mindess, S. Fibre Reinforced Cementitious Composites, 2nd ed.; Taylor \& Francis: London, UK, 2007.

9. Alberti, M.G.; Enfedaque, A.; Gálvez, J.C.; Ferreras, A. Pull-out behaviour and interface critical parameters of polyolefin fibres embedded in mortar and self-compacting concrete matrixes. Constr. Build. Mater. 2016, 112, 607-622. [CrossRef]

10. Babafemi, A.J.; Boshoff, W.P. Pull-out response of macro synthetic fibre from concrete matrix: Effect of loading rate and embedment length. Constr. Build. Mater. 2017, 135, 590-599. [CrossRef]

11. Sivakumar, A.; Santhanam, M. A quantitative study on the plastic shrinkage cracking in high strength hybrid fibre reinforced concrete. Cem. Concr. Compos. 2007, 29, 575-581. [CrossRef]

12. Qian, C.Y.; Stroeven, P. Development of hybrid polypropylene-steel fibre-reinforced concrete. Cem. Concr. Res. 2000, 30, 63-69. [CrossRef]

13. Banthia, N.; Gupta, R. Hybrid fiber reinforced concrete (HyFRC): Fiber synergy in high strength matrices. Mater. Struct. 2004, 37, 707-716. [CrossRef]

14. Banthia, N.; Soleimani, S.M. Flexural response of hybrid fiber-reinforced cementitious composites. ACI Mater. J. 2005, 102, 382-389.

15. Pons, G.; Mouret, M.; Alcantara, M.; Granju, J.L. Mechanical behaviour of self-compacting concrete with hybrid fibre reinforcement. Mater. Struct. 2007, 40, 201-210. [CrossRef]

16. Singh, S.P.; Singh, A.P.; Bajaj, V. Flexural fatigue strength of hybrid fibrous concrete beams. Constr. Mater. Proc. Inst. Civ. Eng. 2012, 165, 99-110. [CrossRef]

17. Bajaj, V.; Singh, S.P.; Singh, A.P.; Kaushik, S.K. Flexural fatigue analysis of hybrid fibre-reinforced concrete. Mag. Concr. Res. 2012, 64, 361-373. [CrossRef]

18. Ganesan, N.; Indira, P.V.; Sabeena, M.V. Tension stiffening and cracking of hybrid fiber-reinforced concrete. ACI Mater. J. 2013, 110, 715-721.

19. Gribniak, V.; Tamulenas, V.; Ng, P.L.; Arnautov, A.; Gudonis, E.; Misiunaite, I. Mechanical behavior of steel fiber-reinforced concrete beams bonded with external carbon fiber sheets. Materials 2017, 10, 666. [CrossRef]

20. Gribniak, V.; Ng, P.L.; Tamulenas, V.; Misiūnaitė, I.; Norkus, A.; Šapalas, A. Strengthening of fibre reinforced concrete elements: Synergy of the fibres and external sheet. Sustainability 2019, 11, 4456. [CrossRef]

21. Chalioris, C.E.; Kosmidou, P.-M.K.; Karayannis, C.G. Cyclic response of steel fiber reinforced concrete slender beams: An experimental study. Materials 2019, 12, 1398. [CrossRef]

22. Dev, A.; Chellapandian, M.; Prakash, S.S.; Kawasaki, Y. Failure-mode analysis of macro-synthetic and hybrid fibre-reinforced concrete beams with GFRP bars using acoustic emission technique. Constr. Build. Mater. 2020, 249, 118737. [CrossRef] 
23. Bhosale, A.B.; Prakash, S.S. Crack propagation analysis of synthetic vs. steel vs. hybrid fibre-reinforced concrete beams using digital image correlation technique. Int. J. Concr. Struct. Mater. 2020, 14, 57. [CrossRef]

24. Zhang, H.; Yu, R.C. Inclined fiber pullout from a cementitious matrix: A numerical study. Materials 2016, 9, 800. [CrossRef]

25. Ashrafi, S.A.; Miller, P.W.; Wandro, K.M.; Kim, D. Characterization and effects of fiber pull-outs in hole quality of carbon fiber reinforced plastics composite. Materials 2016, 9, 828. [CrossRef]

26. Garnevičius, M.; Plioplys, L.; Gribniak, V. A bond model of synthetic macro-fibre in concrete. In Proceedings of the 13th Fib International PhD Symposium in Civil Engineering, Paris, France, 26-28 August 2020; pp. 33-39.

27. Collepardi, M.; Olagot, J.J.O.; Troli, R.; Skarp, U. Influence of amorphous colloidal silica and the properties of self compacting concretes. In Innovations and Developments in Concrete Materials and Construction; Dhir, R.K., Hewlett, P.C., Csetenyi, L.J., Eds.; Thomas Telford: London, UK, 2002; pp. 473-483.

28. Santos, S.F.; Rodrigues, J.A.; Tonoli, G.H.D.; Almeida, A.E.F.S.; Savastano, H., Jr. Potential use of colloidal silica in cement based composites: Evaluation of the mechanical properties. Key Eng. Mater. 2012, 517, 382-391. [CrossRef]

29. Yoo, D.Y.; Shin, H.O.; Yang, J.M.; Yoon, Y.S. Material and bond properties of ultra high performance fiber reinforced concrete with micro steel fibers. Compos. Part B Eng. 2014, 58, 122-133. [CrossRef]

30. Iqbal, S.; Ali, A.; Holschemacher, K.; Bier, T.A. Effect of change in micro steel fiber content on properties of high strength steel fiber reinforced lightweight self-compacting concrete (HSLSCC). Procedia Eng. 2015, 122, 88-94. [CrossRef]

31. Kovács, I.; Balázs, G.L. Structural Performance of Steel Fiber Reinforced Concrete; Budapest University of Technology and Economics: Budapest, Hungary, 2004.

32. Singh, H. Steel Fiber Reinforced Concrete: Behavior, Modelling and Design; Springer Nature: Singapore, 2017.

33. Chu, S.H.; Li, L.G.; Kwan, A.K.H. Fibre factors governing the fresh and hardened properties of steel FRC. Constr. Build. Mater. 2018, 186, 1228-1238. [CrossRef]

34. Chu, S.H.; Kwan, A.K.H. Fibre factors governing the workability and superplasticizer dosage of SFRC. In Proceedings of the 2nd International RILEM Conference on Rheology and Processing of Construction Materials and 9th International RILEM Symposium on Self-Compacting Concrete, Dresden, Germany, 8-11 September 2019; RILEM: Paris, France, 2019.

35. Acikgens Ulas, M.; Alyamac, K.E.; Ulucan, Z.C. Effects of aggregate grading on the properties of steel fibre-reinforced concrete. IOP Conf. Ser. Mater. Sci. Eng. 2017, 246, 012015. [CrossRef]

36. Zhou, Y.; Xiao, Y.; Gu, A.Q.; Lu, Z. Dispersion, workability and mechanical properties of different steel-microfiber-reinforced concretes with low fiber content. Sustainability 2018, 10, 2335. [CrossRef]

37. Garnevičius, M. Analysis of Technological Solutions for Improving the Bond between Concrete and Synthetic Fiber. Master's Thesis, Vilnius Tech, Vilnius, Lithuania, 2019; p. 66.

38. Gao, X.; Zhang, J.; Su, Y. Influence of vibration-induced segregation on mechanical property and chloride ion permeability of concrete with variable rheological performance. Constr. Build. Mater. 2019, 194, 32-41. [CrossRef]

39. DiFrancia, C.; Ward, T.C.; Claus, R.O. The single-fibre pull-out test-1: Review and interpretation. Compos. Part A Appl. Sci. Manuf. 1996, 27, 597-612. [CrossRef]

40. DiFrancia, C.; Ward, T.C.; Claus, R.O. The single-fibre pull-out test-2: Quantitative evaluation of an uncatalysed TGDDM/DDS epoxy cure study. Compos. Part A Appl. Sci. Manuf. 1996, 27, 613-624. [CrossRef]

41. Caceres, J.M.; Netravali, A.N. A special single-fibre pull-out technique for determining the fiber/cement interfacial bond strength. Adv. Compos. Lett. 2002, 11, 21-26. [CrossRef]

42. Froli, M. Analytical remarks on the anchorage of elastic-plastically bonded ductile bars. Int. J. Mech. Sci. 2007, 49, 589-596. [CrossRef]

43. Ceroni, F.; Darban, H.; Luciano, R. Analysis of bond behavior of injected anchors in masonry elements by means of finite element modeling. Compos. Struct. 2020, 241, 112099. [CrossRef]

44. Wiemer, N.; Wetzel, A.; Schleiting, M.; Krooß, P.; Vollmer, M.; Niendorf, T.; Böhm, S.; Middendorf, B. Effect of fibre material and fibre roughness on the pullout behaviour of metallic micro fibres embedded in UHPC. Materials 2020, 13, 3128. [CrossRef] [PubMed] 
45. Kong, D.Y.; Corr, D.J.; Hou, P.K.; Yang, Y.; Shah, S.P. Influence of colloidal silica sol on fresh properties of cement paste as compared to nano-silica powder with agglomerates in micron-scale. Cem. Concr. Compos. 2015, 63, 30-41. [CrossRef]

46. Won, J.P.; Hong, B.T.; Choi, T.J.; Lee, S.J.; Kang, J.W. Flexural behaviour of amorphous micro-steel fibre-reinforced cement composites. Compos. Struct. 2012, 94, 1443-1449. [CrossRef]

47. Jakubovskis, R.; Kupliauskas, R.; Rimkus, A.; Gribniak, V. Application of FE approach to deformation analysis of RC elements under direct tension. Struct. Eng. Mech. 2018, 68, 345-358.

48. Subramanian, N.; Cook, R.A. Installation, behaviour and design of bonded anchors. Indian Concr. J. 2002, $76,47-56$.

49. Zamora, N.A.; Cook, R.A.; Konz, R.C.; Consolazio, G.R. Behavior and design of single, headed and unheaded, grouted anchors under tensile load. ACI Struct. J. 2003, 100, 222-230.

50. Giresini, L.; Puppio, M.L.; Taddei, F. Experimental pull-out tests and design indications for strength anchors installed in masonry walls. Mater. Struct. 2020, 53, 103. [CrossRef]

51. Alberti, M.G.; Enfedaque, A.; Gálvez, J.C. On the prediction of the orientation factor and fibre distribution of steel and macro-synthetic fibres for fibre-reinforced concrete. Cem. Concr. Compos. 2017, 77, 29-48. [CrossRef]

Publisher's Note: MDPI stays neutral with regard to jurisdictional claims in published maps and institutional affiliations.

(C) 2020 by the authors. Licensee MDPI, Basel, Switzerland. This article is an open access article distributed under the terms and conditions of the Creative Commons Attribution (CC BY) license (http://creativecommons.org/licenses/by/4.0/). 